\title{
Bases para la Historia Constitucional del Perú
}

\section{Domingo García Belaunde}

Los pueblos que no conocen su historia, están condenados a repetirla.

G. Santayana

La incomprensión del presente nace fatalmente de la ignorancia del pasado. Pero quizá es igualmente vano esforzarse por comprender el pasado, si no se sabe nada sobre el presente. M. Bloch

\section{La Historia}

La vinculación entre la historia y el derecho es muy antigua, si bien sus relaciones formales son más bien recientes. Esto es, la historia ha existido desde siempre, pero en cuanto tal, en cuanto quehacer científico, arranca tan sólo del siglo XIX y de sus grandes cultores, tanto en Francia, como en Inglaterra y en Alemania, que sentaron las bases de la disciplina, y que con múltiples desarrollos y matizaciones, llega hasta nuestros días. Igual podríamos decir del derecho.

Pero quizá valga la pena hacer una distinción de la cual parten todos, cuál es, separar el objeto materia de una ciencia, de la ciencia misma. Dicho en otras palabras, entre el objeto de conocimiento y el conocimiento en sí mismo. Y esto que se hace de la historia, también se hace en el derecho, y quizá en esto se parecen, pues aquí empiezan las dificultades. Las modernas tendencias filosóficas han desarrollado bien este punto, haciendo la distinción entre objeto y meta-objeto, o entre lenguaje y meta-lenguaje. Pero veamos más de cerca el problema. 
Es opinión dominante, que la historia se refiere, siempre, a lo pasado. Pasado inmediato o lejano, pero pasado al fin y al cabo. La historia, pues, como quería Croce, apunta a lo "sucedido" (accadutto). A lo que pasó, a lo que no existe más.

Pero este enfoque del pasado, no se refiere sólo a una parcela del pasado, sino a todo el pasado en cuanto tal. Viene a cuento traer aquí al recuerdo ciertos enfoques que en otras épocas, privilegiaban de ese pasado sólo ciertos hechos, ciertos sucesos, ciertos acontecimientos, aparentemente relevantes, descuidando lo que algunos, en ciertos casos desdeñosamente, llamaban la pequeña historia. Así, fue clásico en el siglo XIX y en gran parte del actual, el predominio, a veces exclusivo, de la llamada historia de acontecimientos, centrada, generalmente, en los hechos militares, políticos o diplomáticos. Todo este enfoque, fue por momentos, a raíz de la aparición de la llamada Escuela de los Anales, soslayado para más bien tocar otros aspectos, menos espectaculares, pero quizá tanto o más importantes, y en todo caso, esclarecedores. Así, surgió la idea de analizar otros tópicos, vinculados con la vida comercial o religiosa, relacionados con las clases descuidadas por los historiadores, hasta llegar, en nuestros días, a la historia de las mentalidades, la historia del sexo, la historia de la vida privada, etc. Esto es, la historia vista y analizada como totalidad, en el contexto social. Este enfoque, como era de esperarse, trajo excesos y como reacción, ha hecho reverdecer en los últimos años, la llamada historia de los acontecimientos, tan denigrada otrora, que así ha vuelto a cobrar importancia, si bien con algunas concesiones y observando sus justos límites.

Más es indudable que la historia es una totalidad, y así tiende a ser interpretada en el mundo moderno (no hay historia económica y social, hay historia sin más, en su unidad, dice L. Febvre en Combates por la historia, Planeta, Barcelona 1993, p. 39). Lo que sucede es que, por razones de especialización, las áreas se dividen y ocupan así la atención de especialistas sectoriales, gracias a lo cual las investigaciones van más lejos y profundizan más, pero sin olvidar cuál es el gran marco de referencia, que al fin y al cabo, es la totalidad en el espacio y en el pasado.

Por tanto, la historia es una masa social de hechos, que se dieron en el pasado. Y que son objeto de estudio de una disciplina, que también, curiosamente, llamamos historia. Esto ha hecho que se hayan planteado diversos enfoques, para no confundir los hechos con la ciencia que 
los estudia. Así, para algunos, se podría distinguir entre historia y metahistoria; para otros, entre historia y ciencia de la historia, o si se quiere, entre historia y teoría de la historia. En fin, lo concreto del caso es que por un lado existen los hechos y por otro, la ciencia que los estudia. Si bien los nombres son en cierto sentido convencionales, creo que no estaría mal llamar historia a lo primero, y ciencia histórica o ciencia de la historia a lo segundo (Croce, como se sabe, llama historiografía al estudio de la historia, con lo cual en él se encuentra claramente la diferencia; por un lado, la historia, que son los hechos y por otro, la historiografía, que es el estudio científico de tales hechos; distinción interesante, pero que no ha tenido mucho predicamento).

Si seguimos en esta ruta podemos ir más lejos, y hacer alguna breve referencia a la llamada filosofía de la historia, que es, como su nombre lo denota en una primera aproximación, una reflexión filosófica sobre la historia. Esto, si bien en principio es válido, ha tenido fuertes resistencias, $y$ hay muchos que no la aceptan o simplemente le niegan toda validez. Pero cabe una pequeña aclaración. En principio, tenemos que admitir que la filosofía de la historia, de hecho, existe. Aparecida por primera vez -con ese nombre- en Voltaire en su famoso Ensayo sobre las costumbres y el espíritu de las naciones de 1756 , se ha desarrollado intensamente desde entonces, sobre todo gracias al genio del Hegel, cuyas póstumas Lecciones sobre Filosofía de la Historia, tuvieron tanto predicamento en el siglo XIX y bien entrado el siglo XX. Por tanto, es claro que la filosofía de la historia es de por si una disciplina filosófica, o sea, una parte de la filosofía en cuanto se extiende a reflexionar sobre la materia histórica. Lo que sucede es que tal reflexión debería tener en cuenta los hechos históricos y partir de ellos, y esto a veces no sucede; ya que destacados filósofos como el mismo Hegel, emprenden grandes elucubraciones que al final no se compadecen con la realidad, lo que ha hecho que muchos historiadores le tengan natural desconfianza, y por ende, la rechacen. Así, no sólo Hegel ha sido duramente atacado, sino ya en nuestro siglo, algunos autores como Spengler y también Toynbee (a quienes se considera más filósofos que historiadores).

Adicionalmente, la filosofía de la historia ha puesto en debate una serie de problemas históricos como son los hechos mismos (su no repetición), los problemas epistemológicos, el problema de si la historia se repite o no, y si existen leyes históricas. Y por si no fuera poco, los historiadores polemizan o cuestionan enfoques como el de Raymond 
Aron, e incluso del mismo Popper, cuya Miseria del historicismo - un éxito de librería- nada tiene que ver, según dicen, con el trabajo de los historiadores ni menos aún con lo que ha sido y es el historicismo.

En fin, lo cierto es que la filosofía de la historia existe, y es probable que seguirá existiendo. Lo que sucede es que hay que ver con qué enfoque se hace, y que perspectivas adopta, ya que si bien un filósofo de la historia puede ser muy fiel a los hechos- que son, repetimos, la materia prima del historiador- su punto de partida determina el desarrollo de su posterior reflexión (si es hegeliano, tomista, analítico, marxista, etc., adoptará sus respectivas caracterizaciones). Cabe, pues, cultivarla, sobre la base de saber que estamos ante enfoques filosóficos, que no pueden negar ni desautorizar a los hechos. Y que por cierto, es distinta de la historia, que es ciencia empírica.

Volviendo a la historia o ciencia histórica, recordemos que ella es una reflexión o análisis del pasado, pero de todo el pasado sin compartimentos, si bien es cierto que su análisis permite una sectorialización para fines metodológicos. $\mathrm{O}$ sea, es una ciencia que analiza el pasado. Pero esta definición, siendo verdadera en sustancia, no es completa ni menos aún abarca todo. Y sobre esto hay, como era de esperarse, gran cantidad de definiciones, enfoques, planteos, etc. Por ejemplo, Huizinga afirma que la historia es la forma espiritual en que una cultura se rinde cuentas de su pasado. Carr señala que la historia es un proceso continuo de interacción entre el historiador y los hechos, un diálogo sin fin entre el presente y el pasado. Marrou, por su parte, explica que la historia es el conocimiento del pasado humano. Finalmente, la clásica definición de W. Bauer anota que la historia es la ciencia que trata de describir, explicar y de comprender los fenómenos de la vida, en cuanto se trata de los cambios que lleva consigo la situación de los hombres en los distintos conjuntos sociales, seleccionando aquellos fenómenos desde el punto de vista de sus efectos sobre las épocas sucesivas o de la consideración de propiedades típicas; y dirigiendo su atención principal sobre los cambios que no se repiten en el espacio y en el tiempo.

\section{El Derecho}

Problema parecido ocurre con el Derecho, como ya lo adelantamos. Por un lado, la palabra derecho designa al conjunto de reglas de carác- 
ter fundamentalmente imperativo, que están destinadas a encauzar las conductas humanas en una sociedad determinada. Pero, por otro, el derecho es definido como aquella ciencia o disciplina que precisamente estudia el derecho. Precisemos más esto.

Se acepta, por lo general, que el derecho ha existido siempre. De ahí el viejo aforismo ubi homo, ibi jus [...] . Esto es, que donde existe el hombre, hay sociedad, $y$ en donde existe sociedad, hay derecho. En tal sentido, el derecho es, en sustancia, un conjunto de reglas que ordenan la vida en común. Y éstas se han dado siempre, en todas las sociedades, como lo demuestran los hallazgos arqueológicos (así el Código de Hammurabi del siglo XVIII a.C. y las leyes medo-asirias, del siglo XII a.C.). Esto no significa que tuviesen un grado muy elaborado de lo que era la parte normativa, pero es indudable que la tuvieron, primitiva o rudimentaria, o si se quiere insuficiente, pero la tuvieron. Correspondió a Roma la creación del derecho en forma, esto es, como cuerpo técnico, y eso es precisamente lo que ha dado origen a los numerosos pueblos que acogieron su legado y que conforman lo que los comparatistas denominan derecho romanista (o romano-civilista, o romano-canónico, o romano-germano, o romano-canónico-germano, pero brevitatis causa, lo podemos llamar familia romanista, para distinguirla de la familia sajona o del common law, que es la otra gran formación histórico-jurídica de Occidente).

Pues bien, desde siempre, como queda dicho, existió el derecho, término por cierto más moderno, con lo cual queremos significar que existieron reglas de juego en todas las sociedades, reglas que tenían fundamentos diversos, alcances distintos, con características variadas y sanciones peculiares, pero que tenían un núcleo imperativo, que, en esencia, se mantiene hasta ahora (es decir, hay numerosas normas que son simplemente permisivas o indicativas, como lo ha puesto de relieve Hart, pero el núcleo jurídico siempre es imperativo).

$Y$ si esto es así, advertimos de inmediato lo que muchos han calificado como la historicidad del derecho, lo cual implica tres aseveraciones: por un lado, que el derecho siempre ha existido; por otro, que el derecho se configura de acuerdo a cada coyuntura histórica y se transforma con él; y finalmente, que el derecho, a la larga, perece, no siempre permanece, lo cual es más notorio en las civilizaciones desaparecidas.

En consecuencia, si el derecho es histórico, esto significa que existe un antecedente, un hecho en el pasado que es jurídico, que hay que detectarlo. 
A los operadores del derecho, fundamentalmente el abogado, el juez, el profesor, el jurista, les interesa el derecho vigente, el que es válido aquí y ahora. Esto por cuanto el derecho es parte del entramado social y con él tenemos que contar, si queremos saber que hay de nuestras vidas y cómo nos proyectamos en el futuro. Así, por ejemplo, cualquier ciudadano que tiene ciertas pretensiones o problemas de herencia, le interesará saber que dice sobre esta materia el Código Civil de 1984, actualmente vigente, y no lo que decía el Código Civil de 1936, vigente durante muchos años, pero ahora no vigente, esto es, no válido hoy en día, pues fue derogado hace años.

Esto es lo que interesa al hombre de derecho y al hombre común y corriente, que se relaciona con el derecho.

Pero al historiador busca el derecho del pasado, que es, por lo general, el derecho no vigente. El derecho que no existe hoy con fuerza, es el no derecho, es el derecho derogado, y en cuanto tal, no interesa. Por cierto, sabemos perfectamente que en ciertos ámbitos de manera muy marcada interesa, a veces, el derecho derogado, o sea, el derecho no vigente. Así, en materia penal, no me pueden juzgar por la norma vigente hoy en día, sino por la norma que estaba vigente cuando se cometió el delito, en el supuesto que me sea más favorable, y no con la actual, si es más severa. A veces el derecho derogado, tiene vigencia, pero por cierto tiempo; es lo que se conoce como ultraactividad. Esto también sucede, en otros ámbitos, como en el derecho civil (así, cuando analizamos situaciones que están regidas por los cambios de un código a otro código, y situaciones que se dan con la existencia del llamado "derecho transitorio" o en materia tributaria, en donde es tan debatido el problema de los tributos derogados, pero que son más tarde detectados por la administración tributaria, y que pueden ser objeto de acotación, siempre y cuando no haya operado la prescripción. Pero, por cierto, estas son las excepciones).

Lo frecuente es que el derecho derogado, deje de interesar, y sea remplazado para todos sus efectos, por el derecho vigente.

Por cierto, el derecho vigente también puede tener su pasado; así, si el Código Civil de 1984 se aplicó a una situación determinada de 1990, se trata de una realidad pasada, que interesa como referencia o antecedente, y que sólo puede ser invocada en la medida que en esa época el Código era el mismo. Pero las situaciones pueden haber cambiado, y por eso, tal aplicación judicial del Código Civil en 1990, puede ser objeto de un análisis histórico, pues se trata de historia reciente. 
Ahora bien, ¿cómo enfocamos el pasado en materia jurídica? ¿Es posible decir que el pasado es tan sólo una sucesión de códigos y leyes, y que el análisis del pasado se limita a este exámen exegético de la norma? Creo que la respuesta es negativa. El pasado del derecho se expresa, querrámoslo o no, en hechos, o sea, en personas y en determinadas situaciones a las cuales se les aplica o a las que se invoca un derecho vigente en aquel entonces. Pero el derecho no vigente, o sea, el derecho en cuanto pasado, no es sólo la norma, sino el conjunto de hechos que se mueve alrededor de la norma y con la cual forma una unidad. Esto por cuanto si bien la ciencia jurídica o ciencia del derecho estudia las normas y en consecuencia se centra en ellas, el derecho como experiencia- dentro del cual se da el complejo normativo-, es mucho más amplio, incluye un flujo social en donde precisamente la norma se desenvuelve, desarrolla y aplica. Así, considerando el derecho en cuanto pasado, su historia no es la historia de la norma y su aplicación, sino la historia del flujo normativo que condensa derecho y entorno social en el cual ha vivido. Se trata en consecuencia de una experiencia, que precisamente permite un conocimiento global, y que, en cuanto histórica, es una masa social que atraviesa una porción de tiempo, en unidad de processus.

Por tanto, cuando queremos analizar el derecho no vigente, en tanto existió, el primer paso es indudablemente conocer y estudiar la norma que estuvo vigente en aquel momento, pero no aislada, sino dentro del tejido social en el cual nació, se desenvolvió y aplicó. Existe en el pasado un torrente jurídico que es continuidad, que surge de un tiempo a otro, y sigue un proceso hacia adelante.

Pero este pasado jurídico en cuanto pasado, en cuanto no existente, no es derecho, sino derecho en versión histórica.

\section{Relaciones entre Historia y Derecho}

Aclarado, aún cuando sea en forma preliminar, cuáles son los conceptos de historia y de derecho, veamos sucintamente cuáles son las relaciones entre ambos, en cuanto disciplinas académicas.

Quizá para ello no esté demás ver la estructura científica de cada cual, tal como lo acepta, en general, la moderna epistemología, cuyos resultados aquí vamos a resumir, para los fines que nos interesan. 
En primer lugar, es bueno recordar que la historia, como se ha señalado, se ocupa de los hechos pasados. O sea, de sucesos que se dieron en el pasado, que no pueden repetirse, y que tienen ciertos rasgos de singularidad. Es decir, la materia histórica son hechos, sucesos, datos empíricos, que por cierto requieren una metodología acorde con tales hechos. Clásicamente, la historia ha sido ubicada dentro de las ciencias del espíritu o ciencias de la cultura, membretes de raíz neokantiana, que aún cuando todavía tienen cierta circulación, tienden a ser superados por la más amplia y moderna de ciencias sociales, ya que son ciencias que tienen que ver, primariamente, con hechos ocurridos en la sociedad.

Por otro lado, el derecho consiste en reglas genéricas, abstractas, de carácter general, que pretenden encauzar conductas. Algunos juristas (Ross, entre ellos) lo han calificado en cierto sentido como similar al juego de ajedrez. Al igual que el derecho, el ajedrez no tiene que ver con los hechos y no es ni verdadero ni falso. Adicionalmente, sus reglas deben ser observadas por quienes actúan, a fin de obtener consecuencias válidas. En esto se diferencia de las ciencias sociales que son empíricas, que pretenden obtener la verdad de los hechos y cuyos enunciados pueden ser testados, en el sentido que puedan ser verdaderos o falsos. En el derecho, por el contrario, lo que existe es la validez o la invalidez, que son valores distintos. En el primer caso se ven los hechos y los enunciados que se hacen a partir de ellos. En el segundo, se enuncian reglas que pretenden ordenar conductas en un marco social. Por cierto, estas reglas, en su núcleo básico, están teñidas de valoraciones que son su fundamento, pero esto es algo que metodológicamente puede ser separado del aparato normativo. $Y$ es así, puesto que el derecho tiene fines distintos a los de la historia, y tiene un fin inmediato, que es ajeno a la historia. Se trata, como se ve, de dos disciplinas distintas que tienen objetos distintos.

Así, grosso modo podemos dividir las ciencias en ideales, factuales y normativas. Las primeras son aquellas que no existen en la realidad y que son producto de un ejercicio teórico, como son la lógica y las matemáticas (muchos son los autores que las denominan ciencias formales). Las factuales pueden ser de diverso signo, como son las naturales (física, biología, química, etc) o las sociales (sociología, economía, ciencia política, historia); y que algunos autores conocen como ciencias empíricas. Finalmente, las normativas pretenden analizar normas (de manera especial, el derecho y la moral). 
Si aceptamos este esquema tripartito de manera referencial, salta a la vista que es difícil decir como ambas, historia y derecho, pueden tener relación, moviéndose en distintos niveles epistemológicos y ontológicos.

La relación existe, o puede existir, en cuanto hay un pasado en la vida de ese derecho. Es decir, el derecho, en cuanto medio regulador de conductas, ha tenido que transcurrir en el tiempo, y por tanto, tiene tras de si toda una cadena de acontecimientos que constituyen un continuo vital. El derecho, al igual que cualquier institución humana, tiene historia. He aquí el punto de unión.

\section{Historia del Derecho e Historia del Derecho Constitucional}

El punto de enlace entre la historia y el derecho es, como hemos señalado, la historia del derecho. Esta disciplina, como su nombre lo indica, es una historia (o sea, un registro) de lo que ha sido el derecho. Se trata de una disciplina que busca estudiar una parte de este pasado, vinculado estrictamente con el desarrollo del derecho.

Y aquí surgen de inmediato los problemas. Pues por un lado, estamos ante un enfoque histórico del pasado, que requiere necesariamente el conocimiento y la técnica del historiador. Pero por otro, la materia con la cual se trabaja no es un hecho cualquiera (como una batalla o unas elecciones) sino el desarrollo de un aparato jurídico en una determinada parcela del tiempo. Y esto complica el panorama, puesto que para conocer el derecho, que tiene sus propias categorías, su propia estructura y su propio lenguaje, hay que tener formación jurídica, y muchas veces, ser jurista de oficio.

Ante esta situación, se han dividido los pareceres. Un primer grupo señala que la historia del derecho es historia a secas; o sea, una disciplina histórica. Un segundo grupo indica que la historia del derecho es una disciplina jurídica. Y finalmente, hay quienes sostienen que estamos ante una disciplina mixta o bifronte, que participa de ambas y constituye en cierto sentido un tertium quid.

Sin pretender entrar en esta vieja polémica-que es materia para los especialistas- me permito señalar que la primera opción es la que más me convence. Esto es, que la historia del derecho es una disciplina histórica. Lo es por cuanto su enfoque, su aproach es histórico; su perspectiva también lo es, y su método, aún más (son los métodos genera- 
les de las ciencias sociales, con sus propias características que les exige la realidad histórica: documentos, testimonios, restos arqueológicos, etc.). Es decir, se aborda el derecho, pero con una perspectiva y metodología históricas. Lo que sucede es que como se va a estudiar un derecho que ya no lo es, que no existe, entonces tiene que conocer ese derecho y el investigador necesita categorías jurídicas para entender ese derecho muerto. Lo que significa que el historiador del derecho necesita, aparte de su propia formación histórica, un previo entrenamiento técnico que le permita entender el material jurídico que maneja. Por cierto que esto no es fácil, pero así debe hacerse. De manera parecida, el historiador de la medicina tendrá que saber lo que es la ciencia médica, el historiador de la física, tendrá que conocer esta disciplina, y así sucesivamente.

El problema es que siendo la forma la historia y el contenido el derecho y su entorno, el historiador del derecho se encuentra al final lidiando con dos disciplinas y no solamente con una, lo que vuelve difícil el tránsito por ella. Así, estamos ante dos realidades, que pueden dar lugar a una solución fácil (como es, por ejemplo, la solución mixta, que no resuelve nada) pero que reclama una toma de conciencia sobre lo que es la realidad y la materia por estudiar. No se trata, por tanto, de dos materias yuxtapuestas, sino de dos realidades, una (el derecho) inmersa dentro de otra (el decurso histórico) formando una unidad. La disciplina debe, por tanto, considerarse como histórica. No es jurídica, por la sencilla razón de que el enfoque y la metodología son históricas y de las ciencias sociales, y además no tienen carácter normativo ni son prescriptivas, que es precisamente lo que corresponde y distingue al derecho de los demás saberes.

Pero aún aceptando esta situación, tenemos el problema de ver cómo esto funciona. En efecto, siendo histórica- así lo aceptamos- se desprende fácilmente que no es fácil manejar con destreza ambas disciplinas, y ello hace más complicado un trabajo histórico-jurídico. Por eso es que los historiadores del derecho se ven obligados a hacer este esfuerzo, si bien con óptimos resultados. Pero sí los historiadores son los que más han trabajado en aspectos jurídicos del pasado, no es menos cierto que son numerosos los juristas que han hecho contribuciones al mismo campo, ya que existen juristas que hurgando en las canteras de la historia, hacen contribuciones en el mundo histórico-jurídico. Cuando esto sucede, el jurista, conocedor de su oficio, se compenetra con el 
mundo histórico, estudia la disciplina, y la vincula con el derecho. Por eso, no es inusual ver como juristas y estudiosos del derecho, inmersos en la problemática histórica, dedican sus esfuerzos a la historia del derecho y hacen notables contribuciones. Algo parecido podemos ver en otras disciplinas, como por ejemplo, la historia de la filosofía, que ha sido cultivada especialmente por los filósofos, y la historia de la medicina, que ha sido preferente atención de los médicos (cf. Francisco Romero, Sobre la historia de la filosofía, Universidad Nacional de Tucumán, 1943, quien afirma, respaldado por los hechos, que la historia de la filosofía es obra de filósofos y no de historiadores).

Si seguimos adelante, y nos referimos a la Historia del Derecho Constitucional, podemos hacer algunas precisiones adicionales.

El derecho, como se sabe, es uno solo. Lo que sucede es que dentro de él se encuentran diversas ramas o especialidades, en función de las peculiaridades del ordenamiento jurídico de una sociedad. Así, y dejando de lado la tradicional distinción entre derecho público y derecho privado que viene desde Roma, es obvio que existe el derecho civil, el derecho penal, el derecho procesal (civil, penal, administrativo), el derecho constitucional, etc. Y todas estas ramas del derecho, en cuanto tales, han tenido su historia. Por tanto, existe también una historia del derecho constitucional, que no es más que un enfoque sobre la evolución en el pasado del derecho constitucional. Y por tanto, en cuanto tal, no es más que un capítulo de la historia del derecho en general. Esto es, la historia del derecho constitucional no es más que una parte, pequeña sin duda, de la historia del derecho. Por cierto que como disciplina puede ser tratada en forma aislada, pero sin olvidar que ella es una parte del todo, y así debe ser considerada (existe una historia general y multitud de historias particulares). $Y$ esto se confirma cuando vemos historias del derecho por países, en donde se analiza, en su desarrollo, todo el derecho, incluyendo, por cierto, el desarrollo constitucional (cf. por ejemplo, José Antonio Escudero, Curso de historia del derecho, Madrid 1995; Lawrence Friedman, $A$ history of american law, Simon and Shuster. N.Y. 1985; Antonio Marongiu, Storia del diritto italiano, I. E. Cisalpino- La Goliardica, Milano 1977; José Luis Soberanes Fernández, Historia del derecho mexicano, ed. Porrúa, México 1996).

Pero no siempre se utiliza el membrete completo: Historia del derecho constitucional. Por razones de brevedad, se puede denominar 
también Historia constitucional. Pero esto nos remite a los términos o rótulos empleados, que veremos a continuación.

\section{Los membretes y sus significados}

Con lo que hemos señalado en las líneas precedentes, queda claro qué es lo que significamos. Estamos ante una disciplina histórica, que tiene un aproach y un método histórico, pero que trata sobre un fenómeno jurídico que pasó en el tiempo. Este fenómeno del pasado no es un hecho aislado, es un flujo social, complejo, dinámico, que atraviesa el tiempo, y en el cual vemos actuar a los hombres y a las instituciones en contínua inter-relación. Y lo mismo sucede en relación con la constitución.

Pero este hecho social que es el objetivo de una disciplina académica, no ha tenido un sólo nombre sino varios, y tampoco existe total unanimidad sobre ellos. Más bien, las etiquetas, los nombres, han proliferado de manera asombrosa. Si echamos una rápida ojeada a cualquier catálogo bibliográfico o a las principales producciones sobre la materia, vemos que sin ánimo exhaustivo, tenemos los títulos siguientes (hacemos abstracción del referente a un país o área determinada):

1) historia constitucional, 2) historia del derecho constitucional, 3) historia del constitucionalismo, 4) historia de las constituciones, 5) evolución del constitucionalismo, 6) evolución constitucional, 7) historia institucional, 8) historia de las instituciones, 9) desarrollo histórico del constitucionalismo, 10) evolución histórica del constitucionalismo o del derecho constitucional, 11) evolución constitucional, 12) orígenes del constitucionalismo, 13) orígenes de la democracia constitucional, 14) orígenes del derecho constitucional, 15) constituciones históricas y 16) constitucionalismo histórico.

En esta larga lista, que decididamente no es exhaustiva, tenemos una variedad impresionante de nombres. Muchos son, quizá, incorrectos, reliterativos o pueden ser sinónimos. En otros, puede dar a entender que estamos ante dos realidades (como por ejemplo, distinguir entre historia constitucional e historia de las constituciones, que puede dar origen, en este último caso, a limitarse a un análisis de cada constitución por separado y en forma casi literal y exegética, que hoy no se hace, pues es un enfoque sin seguidores). O en otros, encontramos que 
hay redundancia. Por cierto, también aquí hay un problema de gustos o tradiciones que se dan en cada país.

Es decir, ante esta larga lista, lo que tenemos que ver es que término es el que mejor se acomoda a los usos de la comunidad científica que cultiva la disciplina, y además, cuál es su contenido. Por cierto, que pueden haber diferencias entre ellos, pero aclaremos que para mi propósito, la materia constitucional histórica es la ya señalada; o sea, el discurrir temporal de la constitución, entendida ésta no sólo como un texto, sino como una totalidad político-social que le sirve de soporte, a la cual se aplica y que además le sirve de ruta. $\mathrm{O}$ sea, como flujo histórico-constitucional, sin saltos ni vacios, y como una totalidad en el tiempo que pasó. $Y$ si esto es así, no tengo inconveniente en señalar que la disciplina que lo estudia, bien puede llamarse, sin problemas, como historia constitucional que es un concepto breve, sugestivo y suasorio. Y así lo han hecho los clásicos estudios fundacionales, que se han dado en el siglo pasado, sobre todo en Alemania (Georg Waitz), Inglaterra (W.Stubbs, F.W., Maitland, F. Pollock) y Francia (Fustel de Coulanges, Paul Viollet). Ese ha sido el nombre preferido por los grandes maestros, y no vemos porqué no deba seguir siendo usado hoy día. Por tanto, aceptado el contenido de la disciplina, y ante la pluralidad de nombres utilizados por los estudiosos, que sobre todo encierran gustos, preferencias o tradiciones locales, nos quedamos con el más unívoco y más clásico de todos ellos.

Mención aparte merece el rótulo de "Historia de las instituciones" o "Historia institucional», que ha tenido cierto predicamento, y que con independencia a su propio manejo meramente histórico, se ha cruzado, por así decirlo, con la historia constitucional. Y frente a esta nomenclatura, tenemos tres posturas. La primera señala que la historia de las instituciones y la historia constitucional, son, en rigor, la misma cosa. Así lo reconoce un manual clásico (Cf. Luis G. De Valdeavellano, Curso de historia de las instituciones españolas. De los orígenes al final de la Edad Media, Ediciones de la Revista de Occidente, Madrid 1968), en donde identifica a ambas, si bien en su desarrollo, va más lejos de lo que se propone. La segunda postura señala que la historia de las instituciones es, en puridad, una introducción a la historia del derecho, y en cierto sentido la remplaza o la incluye, como es, más o menos, el enfoque que realizan ciertos sectores de la doctrina argentina (cf. Víctor Tau Anzoátegui y Eduardo Martiré, Manual de historia de 
las instituciones argentinas, ediciones Macchi, Bs. Aires 1996; Víctor Tau Anzoátegui, «El concepto histórico de las instituciones» en Revista de Historia Americana y Argentina, 1963-64, núms 7-8 y Eduardo Martiré, Consideraciones metodológicas sobre la historia del derecho, edit. Perrot, Buenos Aires 1977). Estos autores, dentro de su amplísima bibliografía, han tenido puntos vacilantes al respecto; si bien parece predominar en ellos la tendencia de que la historia institucional engloba a la historia constitucional, es decir, el fenómeno históricoconstitucional se encuentra dentro de él; por tanto, la historia constitucional es parte de ella o simplemente no existe, y su mejor entendimiento sólo puede hacerse dentro de un enfoque institucional.

Finalmente, un tercer enfoque señala que se trata de dos disciplinas distintas, la institucional analiza las instituciones (todas ellas, no una ni dos y no sólo las jurídicas), mientras que la historia constitucional analiza el fenómeno constitucional y por cierto sus instituciones, pero sin extenderse a las demás instituciones, que a la larga disuelven la historia constitucional en otras realidades. Así puede verse, por ejemplo, en el citado manual de Tau y Martiré, en donde no obstante su título y sus propósitos, la parte estrictamente jurídica se encuentra sumergida dentro del cúmulo de datos de carácter social, económico, político, administrativo, etc., y lo constitucional a la larga ha desaparecido, arrollado por la masa de datos presentados.

Por eso, y para evitar problemas, es mejor poner claramente el acento jurídico sobre el enfoque histórico que se realiza. La llamada historia institucional es legítima y ha sido y es cultivada por historiadores, y por cierto, puede servir de apoyo a la historia constitucional, siempre y cuando ni se confunda con ella ni tampoco pretenda desplazarla (aún cuando en forma marginal, Fernand Braudel distingue la historia del derecho de la historia de las instituciones; cf. Escritos sobre historia, FCE, México 1991, p. 216). 
que, por un lado tenemos el nacimiento de la ciencia histórica, y en forma casi simultánea, el nacimiento de la historia del derecho y de la historia constitucional. Pero el nacimiento de la disciplina, nada tiene que ver con el hecho constitucional, que es más antiguo, como lo veremos a continuación.

$\mathrm{Al}$ igual que la historia, el derecho es muy antiguo, y también lo es el constitucionalismo. Se ha hablado, por ejemplo, de un constitucionalismo antiguo (representado por los ordenamientos de las ciudades griegas) y de un constitucionalismo medieval (como por ejemplo, el que se señala en la constitución estamental). Pero en rigor, como técnica, como sistema de gobierno, como interdicción de la arbitrariedad, el constitucionalismo actual nace propiamente a fines del XVIII, como una creación atlántica, es decir, a los dos lados del Atlántico, representado por la Revolución francesa y por la Revolución norteamericana, aún cuando precedidos, en cierto sentido, por la Revolución inglesa de 1688. La primera como expresión de la lucha y la victoria contra el absolutismo reinante, y contra el ancien régimen. Y la segun$\mathrm{da}$, contra el absolutismo del monarca inglés, distante pero efectivo, liderado por los ingleses de las colonias, es decir, por americanos.

Por cierto, el constitucionalismo moderno que nace a fines del siglo XVIII, no nace de la nada. Por el contrario, tiene antecedentes que pueden rastrearse en la reforma, y más antes aún, en la Edad Media y en ciertas experiencias del mundo antiguo, como es el caso de las ciudades griegas. En ese sentido, no hay nada nuevo bajo el sol. Pero sí es menester fijar una partida de nacimiento, y ésta es, sin lugar a dudas, a fines del siglo XVIII. Y es bueno también recalcar que este nacimiento del constitucionalismo es fruto, en realidad, del desarrollo de la idea liberal, que también tiene antecedentes más lejanos, pues es el liberalismo el que crea, precisamente, la idea del poder controlado y de la protección de los derechos del ciudadano frente a los excesos del Estado (cf. G. Burdeau, El liberalismo político, EUDEBA, Bs. Aires 1983). Por tanto, en sentido estricto, naciendo el constitucionalismo a finales del siglo XVIII, la respectiva historia debe datarse también en esta época, o sea, partir de aquí. Pero esto no siempre se hace. Hay muchos historiadores que al redactar las respectivas historias constitucionales de sus pueblos se remontan a períodos muy lejanos, (así Stubbs con relación a Inglaterra, se retrotrae hasta la Carta Magna, por explicables razones). Nada impide, por cierto, este retroceso de la línea demarcatoria, pero 
sobre la base de tener presente que lo que nos interesa, en realidad, es el constitucionalismo moderno, que es, en puro rigor, el constitucionalismo en sentido estricto, aún cuando no podamos desconocer sus orígenes y la trayectoria de sus antecedentes.

$\mathrm{Si}$ analizamos este dato, caemos en la cuenta que el nacimiento del constitucionalismo coincide, sin querer, con la clásica periodificaciónmuy difundida y también muy cuestionada- de la historia en antigua, media, moderna y contemporánea. Esta periodificación cuatripartita, fabricada con evidente óptica eurocentrista, es sin lugar a dudas falsa, ya que explica lo que sucedía en Europa, pero no lo que sucedía en otras partes del mundo. Sin embargo, cabe acotar que dicha periodificación, sobre todo a partir del último período, o sea, el que señala que ingresamos al período contemporáneo a fines del siglo XVIII, es parcialmente aplicable a las naciones latinoamericanas, que precisamente por ésa época empiezan a sacudirse de la tutela colonial e inician el largo proceso de emancipación frente a la corona española. De tal suerte, habría, sin lugar a dudas, un total desfase con las tres primeras etapas, pero una cierta coincidencia o rasgos de verdad que se advierten en la última etapa. Por tanto, admitiendo que las fechas no son rígidas (toda fecha es necesariamente aproximada, pues aquí es válida para los hechos la tesis del tiempo largo elaborada por Braudel), hay cierta coincidencia entre el desarrollo histórico- e histórico constitucional europeo-, con el desarrollo histórico-constitucional latinoamericano.

Por tanto, el constitucionalismo prácticamente coincide con el inicio de la llamada convencionalmente "edad contemporánea," y sus etapas sucesivas- en un mundo cada vez más cercano y cada vez más unido, que desemboca en la globalización de los últimos años.

Con posterioridad a esa etapa inicial, que puede llamarse el "primer momento constitucional», existe un largo período de afianzamiento del Estado constitucional- liberal, que dura hasta el fin de la Gran Guerra, es decir, hasta 1918, si bien dentro de él pueden albergarse, quizá, ciertas sub-épocas por sus peculiaridades. Luego viene un período agitado y enriquecedor(1918-1945) que es en realidad de transición. Y con posterioridad, empieza un «tercer momento constitucional» luego de la segunda postguerra, que dura hasta nuestros días. Naturalmente, ésta es una clasificación global, que tiene un valor referencial, y que ayuda a explicar lo que sucede en el mundo occidental, y que si bien explica los momentos, las tendencias y las caracterís- 
ticas más generales, no significa que se aplique mecánicamente a la realidad de todos los movimientos constitucionales de cada uno de los países latinoamericanos (y esto por cuanto cada uno de ellos tiene sus propias circunstancias y peculiaridades en su desarrollo).

Por cierto, para hablar propiamente de una historia constitucional, hay que tener constitución o documento legislativo o costumbres jurídicas que hagan las veces de tales. Esto es, la presencia de una norma de alto rango que tenga determinadas características. Las constituciones en sentido moderno (estructura de los poderes y derechos de los ciudadanos), sólo se fortalecen y difunden a fines del siglo XVIII. El siglo XIX fue el siglo de la lucha por las constituciones. Y el siglo XX es el de la universal propagación de ella, y por tanto de su excesiva difusión, el de su transformación y también el de su crisis.

\section{Constitucionalismo peruano}

El Perú inicia materialmente su proceso emancipatorio de España en 1820, cuando las tropas del general San Martín desembarcan en territorio peruano en la bahía de Paracas, a 300 kilómetros al sur de Lima. $\mathrm{Al}$ año siguiente, proclama su independencia, definiéndose por la república en 1822. Desde entonces, empezó una larga historia constitucional que llega a nuestros días.

Pero la historia no comienza estrictamente en 1820 , sino mucho antes. Los esfuerzos independentistas se inician en 1780, en forma lenta, pero segura, y culminarán años después, sellándose en 1824 la independencia sudamericana en los campos de Ayacucho y gracias al genio militar de Bolívar. Antes de la historia, existe, pues, una pre-historia constitucional, si así queremos llamarla por comodidad. Ella empieza en 1780 y termina en 1820 , en que empieza propiamente nuestra historia. En este período suceden, sin embargo, dos aspectos interesantes, vinculados con la invasión napoleónica a España, que en cierto sentido fue cataclísmica. La primera es la Constitución de Bayona de 1808, constitución otorgada, hecha por una asamblea especialmente convocada, con la representación de un peruano, y que contemplaba al Virreynato del Perú entre las posiciones de ultramar (cf. Carlos Sanz Cid, La Constitución de Bayona, Edit. Reus, Madrid 1922, p.110). Pero esta Constitución, si bien recibida con agrado por ciertos sectores 
españoles que creían ver en ella una cierta modernización que estaba ajena al régimen absolutista de Carlos IV, no fue aplicada nunca y jamás fue reconocida. En realidad, se quedó en el papel y jamás se supo de ella en los dominios americanos, sino muy tardíamente, y como curiosidad histórica. El segundo hecho importante es la Constitución de 1812, discutida y aprobada en Cádiz, que tuvo un amplio componente democrático, en la cual participaron un buen número de representantes americanos(entre ellos quince del Perú), y que aquí fue conocida y jurada en todas las plazas. Aún más, puesta en vigor. Tales empeños, sin embargo, naufragaron tan pronto retornó al poder Fernando VII en 1814, lo cual, sin lugar a dudas, precipitó los movimientos populares que aspiraban a la independencia de la metrópoli. Este documento fue ampliamente conocido en la época, y tuvo una notable influencia en lo que vino después.

Pero si dejamos de lado estos antecedentes, que en realidad no son constituciones peruanas, pues el Perú como república no existía, sino que era una colonia, provincia, dominio o dependencia de la Corona española, tenemos que partir de la primera constitución peruana de 1823 , que sin embargo, prácticamente no llegó a regir por la continuación de la lucha entre patriotas y realistas y luego por los poderes otorgados a Bolívar. A ella siguió la Carta de 1826, preparada por Bolívar y aprobada por los colegios electorales, que tampoco rigió. Y luego se sancionó la de 1828 , que tuvo corta duración, pero una larga influencia intelectual, que duró más de un siglo.

Luego de la Constitución de 1828, han seguido las siguientes: 1834, $1839,1856,1860,1867,1920,1933,1979$ y 1993 . Es decir, un total de doce constituciones, a las cuales hay que añadir otras leyes, estatutos y normas que hicieron las veces de constitución, en períodos algo agitados de la historia peruana.

Creo que todo este período, puede ser dividido en cuatro grandes etapas:

a) primer período; de 1820 a 1860 ,

b) segundo período; de 1860 a 1920 ,

c) tercer período; de 1920 a 1979 y

d) cuarto período; de 1979 en adelante.

Esta periodificación la hemos efectuado teniendo en cuenta, a) la situación de independencia política del Perú, en relación con España, 
b) la dación de importantes constituciones, que marcaron o coincidieron con períodos importantes y de largo aliento de nuestra historia política, c) la coincidencia con épocas de tranquilidad política, desarrollo económico o punto de partida de épocas con características distintas; d) el inicio o el restablecimiento de la democracia en sentido plena y e) la intensidad del debate doctrinario y su influencia.

Por cierto, toda clasificación en convencional y en cierto sentido operativa. Aún más, las fechas no son exactas. Así, por ejemplo, cuando los historiadores clásicos decían que el mundo antiguo había fenecido en el año 476 con la invasión de Roma por los bárbaros, se daba a entender que esa caída se produjo de inmediato, casi de golpe y en un sólo año, en el cual los pueblos del norte arrasaron a la civilización romana de Occidente. Este dato no es exacto, pues el desmoronamiento del mundo antiguo y la pérdida de las fronteras en el mundo romano por las incursiones de los bárbaros, no fue cosa de un sólo día, sino de varios ańos, si bien es cierto que hay un momento en que se da un precipitado de situaciones o una inflexión que puede significar el final de un período o su punto de no retorno. Esto es, las fechas son solamente referenciales, motivo por el cual usar un año u otro, más aún cuando están cercanos, es algo quizá irrelevante.

Por cierto, que esta clasificación la podríamos aligerar, es decir, hacerla más flexible, y así tendríamos:

a) primer período, de declaración de la independencia y de lucha por la afirmación de la democracia liberal, que podría ir de 1820 a 1919;

b) un segundo período que podría partir de 1920, en que finaliza en términos generales la bella época o la república aristocrática (en terminología de Basadre) y que llega hasta 1979.

c) Un tercer período que parte de 1980, con un país que ha crecido, en población, en economía y en exigencias y que además se ha incorporado al mundo moderno y se prepara a la globalización. Todo esto, por cierto, con alzas y bajas.

Pero el problema es que cuando más extensas o más amplias sean nuestras periodificaciones, abarcan mucho más, pero pierden en intensidad y alcance explicativo, se quedan en generalidades, $y$ al final para ganar rigor tenemos que recurrir a los sub-períodos al interior de cada uno de ellos. Esto se puede hacer, pero dejamos anotado aquí nuestro 
intento; lo que pensamos sobre la periodificación constitucional peruana, y cuáles son sus limitaciones.

\section{Quiénes han hecho Historia Constitucional peruana}

Un recuento de quienes en el Perú republicano han hecho historia constitucional peruana, sería muy largo. En efecto, todos los historiadores, de forma más o menos explícita, detallada o sumariamente, han tocado el tema constitucional, con singular y variada fortuna. Pero lo que nos interesa es ver los de que manera específica se han dedicado a ello. $\mathrm{Y}$ así existe consenso en que el primer trabajo sobre nuestra historia constitucional lo hizo Toribio Pacheco, en un breve folleto titulado Cuestiones constitucionales, publicado, como primera parte, en Arequipa y en 1854 (una programada segunda parte, de la cual llegó a adelantar artículos sueltos, no llegó a ser publicada como libro, por la inestabilidad política de la época y la muerte prematura de Pacheco).

Este folleto, casi desconocido, y que acaba de ser reeditado (Editorial Grijley, Lima 1996) es breve, y es una crítica de nuestras constituciones que llega hasta la de 1839 , vigente en la época en que la obra fue dada a la imprenta. No es simplemente una exégesis de los textos, sino un análisis político global, desarrollado sobre un trasfondo histórico y utilizando un andamiaje jurídico. Sin embargo, no es en realidad un trabajo hecho con metodología histórica. Pacheco era hombre con una amplía formación humanista y romanista, con lecturas de autores clásicos, que le sirvieron para hacer una buen panorama y un estupendo análisis. Pero no se atuvo al rigor del método histórico, que él no conocía y que además estaba muy en sus comienzos en la época que él escribió. Además, Pacheco era un hombre de acción; dedicado a la política, en donde destacó de manera singular, y dedicado, además, al estudio del Derecho Civil, como se demuestra en su Tratado de Derecho Civil que nunca llegó a terminar, pero que fue, sin lugar a dudas, el mejor texto civilista de todo el siglo XIX y bien entrado el siglo XX (a tal punto, que hubo muchos que se dedicaron a completarlo como es el caso de Ricardo Ortíz de Zevallos y Vidaurre en 1906).

Poco tiempo más tarde, Manuel Atanasio Fuentes, publicista de amplia trayectoria, político, periodista, autor de textos costumbristas y otros de temática variada, escribió un Derecho Constitucional Univer- 
sal e Historia del Derecho Público Peruano (2 tomos, Lima 1874) que es de interés. La importancia de Fuentes para el derecho, en general, y para el derecho constitucional en particular, es relevante, sobre todo por lo mucho que escribió y por lo que tradujo (en especial los textos de Pradier Foderé, de tan larga influencia en nuestro medio). Pero Fuentes, en la parte histórica que es la que propiamente nos interesa, se dedicó a hacer algunos comentarios sueltos y episódicos, de carácter exegético y más bien centró sus esfuerzos en publicar y traducir textos constitucionales extranjeros, así como los textos constitucionales peruanos, pero en forma temática, que si bien útil, impedía ver la unidad del documento legal en su conjunto. El trabajo de Fuentes fue, en realidad, de divulgación y ordenamiento sistemático de textos, utilizando un criterio cronológico y exegético de los textos históricos, y además, sin ninguna óptica histórica (así, divide el derecho público peruano en tres épocas: incaica, dominación española e independencia, cit. Tomo 2, p. 5).

En el monumental Diccionario de la Legislación Peruana (edición definitiva en 2 tomos, París 1879), Francisco García Calderón Landa, dedicó numerosas voces de la legislación relacionadas con la Constitución peruana vigente de 1860 y su desarrollo, explicando en muchos casos los antecedentes históricos y legislativos, concordancias y aplicaciones, si bien no trató en concreto la temática constitucional. Fue, no obstante, una obra de gran aliento, cuyas voces por materias bien podrían reproducirse hoy en día.

En el presente siglo hay que destacar el esfuerzo de Lizardo Alzamora Silva (Evolución política y constitucional del Perú independiente, de 1942 y Programa razonado de Derecho Constitucional del Perú, primera parte, Historia Constitucional del Perú, Lima 1944) que son dos grandes enfoques, el primero más breve, el segundo más bien extenso, pero exegético, comprimido y sin pretensiones explicativas como el primero.

Con posterioridad, debemos mencionar a José Pareja Paz Soldán, quien publica en 1944, una voluminosa Historia de las constituciones nacionales, en donde desarrolla en sucesivos capítulos, cada una de las constituciones y estatutos del Perú republicano, hasta la fecha de la edición de su libro. La obra tiene un referente político de fondo, y si bien los acontecimientos tienen cierta unidad, se acepta una clasificación partiendo de cada una de las constituciones, lo cual no es lo más recomendable. 
Luego, Pareja publicó un texto sobre Derecho Constitucional Peruano en 1951, que era un tratamiento exclusivo de la carta vigente en aquel entonces (la Constitución de 1933) y al que incorporó como primera parte y debidamente revisado, su texto de historia constitucional, formando una unidad que desde entonces ha tenido el éxito de varias ediciones, y ha gozado de una circulación privilegiada. La última edición de esta obra, notablemente aumentada, actualizada y mejorada con más amplias perspectivas, se titula Derecho constitucional peruano y la Constitución de 1979 (Lima, 1984, con reimpresiones en dos tomos).

El esfuerzo de Pareja es, sin lugar a dudas, el de mayor aliento hasta la fecha, ya que partiendo de una realidad histórica, en sus vertientes políticas y sociales, ha tratado de explicar nuestros movimientos políticos y sucesivos textos constitucionales. Falta en la obra de Pareja algunas precisiones técnicas, y sobre todo utilización de mayores fuentes, pero, en general, se trata de un panorama muy sugestivo.

Con posterioridad, Vicente Ugarte del Pino, historiador del derecho y profesor universitario de la materia-al igual que Pareja-, publició en 1978, una Historia de las constituciones del Perú, cuyo título en realidad es engañoso. Lo que intentó hacer Ugarte, fue una compilación de todas nuestras constituciones, que es en realidad el contenido de la obra, y a ello añadió, a manera de presentación de cada una de ellas, unas cuántas páginas relacionadas con la historia de esa constitución, pero sin hacer referencia a la problemática histórico-constitucional. No es, pues, una historia constitucional peruana, pues no guarda coherencia ni un plan de conjunto, sino que son textos yuxtapuestos de cada constitución, presentados de manera fragmentaria, y como independientes entre sí. En realidad, es una compilación documental de nuestras constituciones, precedidas cada una por una nota de presentación y ubicación histórica.

Aparte de estos panoramas generales, hay estudios parciales y monográficos hechos más bien por historiadores, y sólo en fecha reciente se han hecho estudios puntuales sobre aspectos de nuestra historia constitucional (así los de Pedro Planas, sobre la república autocrática y la descentralización; Valentín Paniagua, sobre aspectos políticos y electorales, Edgar Carpio Marcos, sobre la enseñanza del Derecho Constitucional; Daniel Soria, sobre el Consejo de Estado en el siglo XIX, y Carlos Mesía, sobre el pensamiento constitucional en el siglo 
XIX). Y sin olvidar los ensayos de Javier Vargas sobre las constituciones de 1839 y 1860 .

Las historias generales tratan, por lo general, aspectos constitucionales, tanto las hechas con fines académicos, como las realizadas con ánimo de manual o de divulgación, aún cuando no siempre presentan rigor y claridad. Escapa a esta relación, la monumental Historia de la República del Perú (11 tomos, ed. póstuma, Lima 1983) de Jorge Basadre, en donde se encuentran numerosos apartados, sólidos y bien fundamentados, sobre aspectos constitucionales de nuestra historia, si bien sólo llega hasta 1933. Esta obra se mantiene como de uso obligado para el estudioso.

\section{Lo que se espera de una Historia Constitucional peruana}

No obstante existir en nuestro país una tradición historiográfica respetable (que en realidad parte de José de la Riva Agüero, con su famosa tesis de 1910 sobre La Historia en el Perú) la historia constitucional casi no se ha trabajado, pues lo que existe es realmente muy poco. $\mathrm{O}$ muy promisorio y muy incipiente (como en Toribio Pacheco) o excesivamente documental (Fuentes y Ugarte del Pino), o demasiado general (como es el caso de Pareja Paz-Soldán, quien sin embargo, es autor, hasta ahora, del mejor texto sobre historia constitucional peruana). Y ello es difícil pues, como decíamos anteriormente, se necesita un conocimiento histórico, pero también una cobertura constitucional, que no son muy complejos, pero que tampoco son fáciles de encontrar, pues ello toma tiempo y en cierto sentido una vocación alimentada de dos vertientes. Pero anotemos que el mejor esfuerzo global existente, ha sido obra de un jurista (Pareja) y no de un historiador.

Vistas así las cosas, y antes de pensar en tratados inmanejables y que nunca se terminan, es conveniente pensar que lo mejor que se puede hacer en los actuales momentos, es presentar un manual general, pero hecho, en la medida de lo posible, con fuentes directas o apoyándose en monografias e investigaciones confiables. Dicho en otras palabras, presentar en un volumen nuestra historia constitucional, pero teniendo presente los siguientes puntos: 
a) Debe ser una historia constitucional, que haga referencia y que parta de la historia,

b) Debe partir de los hechos, esto es, de determinados hechos políticosociales ocurridos en el país desde 1820, y eventualmente retrocederlo antes, en especial, contando entre sus antecedentes con las Cortes de Cádiz.

c) Debe analizar los debates públicos que se dan al nivel de lo que convencionalmente podemos llamar la clase política: presidentes, parlamentarios, dirigentes, grupos de presión.

d) Debe prestar atención, de manera preferente, a los diarios de debates, para ver la manera como surgieron los textos y que los motivaron (en la medida en que esto es posible).

e) Debe tener presente algunos textos doctrinarios que han tenido influencia (como es el caso de Pinheiro o Ahrens).

f) Debe tener en cuenta la efectividad de las normas y la vigencia de las instituciones (a nivel político, legislativo y jurisprudencial).

g) Finalmente, aún cuando esto es más complicado, y bien puede dejarse para más adelante, es importante revisar algunos diarios y revistas de la época, en la medida que recojen debates u opiniones que en determinado momento tuvieron eco.

Naturalmente, una historia constitucional peruana así pensada, es un proyecto de largo alcance. Pero hay que comenzar en algún momento, y con el tiempo, vendrán otros a completar la obra, de manera tal que poco a poco se alcance un buen nivel académico. Por cierto, esto no impide que en forma previa o paralela, se hagan investigaciones puntuales que sirvan luego para apuntalar una historia general (que pueden ser de carácter horizontal o vertical).

Cabe resaltar también que en la parte relacionada estrictamente con los hechos, el historiador constitucional debe apoyarse básicamente en los trabajos hechos por historiadores de oficio, que en nuestro país tienen una labor muy destacada (así, por ejemplo, existen multitud de monografías sobre procesos políticos, sobre guerras, revoluciones, aspectos internacionales, debates políticos, relaciones con la Iglesia, descentralización, comportamientos judiciales, etc.), que pueden servir como un buen punto de partida.

No queda, pues, más que echarse a andar. 
Lima, julio de 1998.

\section{Apéndice}

Comentarios y notas bibliográficas: En el primer semestre de 1997, a pedido de César Landa, quien partía al extranjero por un año, me hice cargo, conjuntamente con Carlos Ramos Núnez y Carlos Mesía Ramírez, del curso de Historia Constitucional del Perú, que regularmente se dicta en la Maestría en Derecho Constitucional de la Escuela de Graduados de la Universidad Católica. El curso fue dividido, para efectos de dictado, y yo me hice cargo de la parte introductoria, que cubría tres horas. Fue así que me puse a revisar mis viejos apuntes sobre la materia, que en realidad se retrotraen al período 1977-1978, cuando dentro del seminario que tenía a mi cargo en el entonces Programa Académico de Derecho, dediqué largas horas a la historia constitucional peruana. Recuerdo que en aquella época, consulté lo que pude, pero sobre todo recurrí a la amistad y al consejo de Jorge Basadre, en la cumbre de sus años, pero muy solícito y muy lúcido. Basadre me orientó en algunas lecturas básicas, en aspectos metodológicos y sobre todo en puntos concretos de nuestra historia, orientándome en lo relativo a las fuentes. Fruto de esos afanes fue una compilación fidedigna de las constituciones del Perú, que concluida en 1979, solo logré editar, debidamente revisada y ampliada, en 1993. Pues bien, en esta oportunidad iba a retomar el camino, aún cuando no de la totalidad del curso -pues el tiempo que disponía no me lo permitía,- y adicionalmente por cuanto contaba con muy competentes colaboradores para ello. Por tanto, consideré oportuno en esta parte preliminar, hacer una especie de prolegómenos a la disciplina y a los problemas que ella afrontaba. Grande, sin embargo, fue mi sorpresa, al constatar que los historiadores del derecho constitucional que pude revisar, hacían un ingreso directo a su temática, sin plantearse los supuestos de su ciencia. Por otro lado, los historiadores del derecho, generalmente hacían lo mismo, y tan sólo los historiadores (los prácticos y los teóricos) hacían hincapié en esos supuestos que a mi tanto me interesaban. No tuve, pues, más remedio que buscar esas fuentes, ya que mis clases, y el presente ensayo que es un reflejo de ellas, estaban dirigidas a juristas, y sobre todo a constitucionalistas, y no a historiadores. Esto explica que aquí se hagan 
referencias que para el historiador profesional pueden parecer superfluas, pero para el historiador constitucional o historiador del Derecho, no lo sean tanto, y más aún para el estudioso que se interese en el área. Esto es, se trata de presentar, a nivel de historia constitucional, los problemas de esta disciplina, que siendo conocidos por los profesionales del oficio, no son generalmente tocados por los que hacen historia constitucional, como puede constatarlo quien revise la bibliografia existente.

De ahí mi interés en señalar, en esta parte, alguna bibliografía seleccionada sobre los principales problemas que trata este ensayo, con algunos comentarios y reflexiones adicionales, cuando éstos son pertinentes. Demás está decir, que son varias las personas que, de una u otra manera, me han ayudado, o mejor, orientado en esta búsqueda. De ellas debo mencionar especialmente a Dardo Pérez Guilhou, amigo de muchos años, y dedicado, sobre todo, a la parte histórico-institucional desde Mendoza, en donde lleva a cabo una labor admirable, como lo he puesto de relieve en otra oportunidad. Pérez Guilhou no sólo personalmente, sino a través de un epistolario muy fluido, tuvo la inmensa gentileza de hacerme acertadas observaciones sobre los alcances de la historia del derecho, de la historia constitucional y de la historia institucional; aún más, me puso al corriente de los usos y tendencias existentes en la comunidad histórico-jurídica argentina, y me proporcionó numerosas fotocopias de trabajos que de otra manera no hubiera podido conseguir. Fue también de gran apoyo el que me brindó mi antiguo alumno y hoy mi colega, Francisco J. del Solar, quien a fuer de abogado, es master en historia, y me proporcionó frondosa bibliografía y en especial los libros que más se usaban en las aulas de la Universidad Católica, y que hoy, por esas cosas del destino, o no existen o no llegan a librerías. Oportuno apoyo bibliográfico me proporcionaron José F. Palomino Manchego, Edgar Carpio Marcos y Alexksandar Petrovich; éste último sobre literatura inglesa y norteamericana. Mi antigua compañera de estudios universitarios Cristina Florez, me orientó en la bibliografía francesa, que tan bien conoce. César Landa me dió información sobre la literatura alemana. Igualmente cordiales fueron los apoyos que me brindó mi dilecto amigo Francisco Fernández Segado. Jorge Basadre Ayulo, como siempre, comentó conmigo varios puntos aquí tratados, e igual lo hizo Pedro Planas. José de la Puente Brunke leyó los originales y me hizo valiosos comentarios y sugerencias. Estas referencias, por cierto, no enervan la responsabilidad de mis errores. 
Los problemas epistemológicos en materia de ciencias, son objeto de una muy frondosa literatura; sin ánimo exhaustivo, señalaré la siguiente: Jean Piaget, Logique et connaissance scientifique, Gallimard, Paris 1967 (existe traducción castellana en varios volúmenes); Bertrand Russell, La perspectiva científica, Ariel, Barcelona 1969; R. Blanché, La epistemología, Oikos-Tau, Barcelona 1973. Descomunal por sus dimensiones, pero siempre sugerente y certera, es la obra de Mario Bunge, La investigación científica, Ariel, Barcelona 1980.

Sobre los aspectos teóricos del derecho, cf. José Manuel Delgado Ocando, Curso de filosofía del derecho actual, Vadell hnos editores, Caracas 1994 (libro muy útil, y con perspectiva moderna, que lo diferencia grandemente de la gran cantidad de manuales que se inspiran en cánones vigentes en la década del treinta y aún antes). Igualmente importantes, Manuel Atienza, Introducción al Derecho, Barcanova, Barcelona 1985 (el título no corresponde al contenido; se trata, en realidad de una introducción, muy bien montada, a la teoría del derecho, o si se quiere, a la filosofía del derecho, con importantes referencias a los saberes conexos, como son la lógica jurídica y la sociología del derecho); Carlos Santiago Nino, Introducción al análisis del derecho, Edit. Astrea, Buenos Aires 1980; hay ediciones posteriores (este libro, tras la prematura muerte de su autor, puede considerarse como definitivamente concluído; es sin lugar a dudas, uno de los grandes manuales de los últimos años); útil también, Albert Calsamiglia, Introducción a la ciencia jurídica, Ariel, Barcelona 1986.

Sobre la historia y su concepto, existe una literatura inmensa. Pero vale la pena recurrir a los textos teóricos que sobre su oficio han hecho grandes historiadores; entre otros, pueden verse; L. Febvre, Combates por la historia, edit. Planeta, Barcelona 1993; Edward H. Carr, ¿Qué es la historia? Ariel, Barcelona 1991; Marc Bloch, Apología para la historia o el oficio del historiador, FCE, México 1996 (a página 155 corre la cita que antecede a este ensayo); Johan Huizinga, El concepto de la historia y otros ensayos, FCE, México 1994; Pierre Vilar, Iniciación al vocabulario del análisis histórico, ed. Cátedra, Barcelona, 1982; G. Duby, Diálogo sobre la historia, Alianza, Madrid 1988; Gordon Childe, Teoría de la historia, Pléyade, Buenos Aires 1976; F. Braudel, La historia y las ciencias sociales, Alianza, Madrid 1990 (contiene el 
famoso ensayo sobre la larga duración); Arnold J. Toynbee, La civilización puesta a prueba, Emecé, Buenos Aires 1954(son ensayos sueltos, que sin embargo contienen algunos enfoques sobre el trabajo del historiador); Henri I. Marrou, El conocimiento histórico, edit. Labor, Barcelona 1968; Peter Burke Formas de hacer historia, Alianza, Madrid 1994; (es un interesante libro colectivo, con ensayos dedicados a la historia desde abajo, la historia oral, la historia de las lecturas, la historia del cuerpo, la historia de las imágenes, historia de las mujeres, etc). Jacques Le Goff, Pensar la historia, Paidós, Barcelona 1997; Josep Fontana, Historia, análisis del pasado y proyecto social, Crítica, Barcelona 1992; Armando Saitta, Guía crítica de la historia y de la historiografía, FCE, México 1996; Carlos Rama Teoría de la historia, Edit. Tecnos, Madrid 1968; Lawrence Stone, El pasado y el presente, FCE, México 1978; Pierre Vilar Pensar la historia, Instituto Mora, México 1995; Eric Hobsbawm Sobre la historia, Crítica, Barcelona 1998, etc.

Sobre algunos aspectos históricos y problemas a él vinculados, cf. R.G. Collingwood, Idea de la historia, FCE, México 1978 (cubre desde la antigüedad a nuestros días); F. Meinecke, El historicismo y su génesis, FCE, México 1982 (es un libro clásico en su género); A. Waismann, El historicismo contemporáneo, edit. Nova, Buenos Aires 1960 (un buen recuento panorámico) y Adam Schaff, Historia y verdad, ed. Crítica, Barcelona 1988( discute el problema de si es posible la objetividad en la historia).

Sobre metodología, aparte de los textos generales, cf. Ciro F.S. Cardoso y H. Pèrez Brignoli, Los métodos de la historia, edit. Crítica, Barcelona 1986 (centrado sobre todo, en la parte demográfica, económica y social); Ciro F.S. Cardoso, Introducción al trabajo de la investigación histórica, edit. Crítica, Barcelona 1989 (ideal para iniciarse); Charles Samaran L'histoire et ses méthodes, ed. Gallimard, Paris 1980 (muy completo); Jerzy Topolsky, Metodología de la historia, edit. Cátedra, Madrid 1985 (muy denso, muy filosófico, pero iluminador). Util como herramienta inicial; cf. Guy Thuillier y Jean Tulard Cómo preparar un trabajo de historia, Oikos-Tau, Barcelona 1988.

Selecciones de textos de historiadores hay muchas; señalemos tan sólo la de Fernando Sánchez Marcos, Invitación a la historia, edit. Labor, Barcelona 1993(cubre de Herodoto a Voltaire); y Patrick Gardiner, Theories of history, The free press, 1960 (parte de Vico y llega hasta nuestros días). 
Sobre la filosofía de la historia tenemos los siguientes panoramas generales; León Dujovne, La filosofía de la historia, edit., Galatea, 2 tomos, Buenos Aires 1958-1959; Karl Löwith, Meaning in history, Anchor, N.Y. 1965 (hay traducción castellana); José Ferrater Mora, Cuatro visiones sobre la historia universal, edit. Sudamericana, Buenos Aires 1967. De la obra de Hegel sobre filosofía de la historia, existen varias versiones; la más conocida es la de José Gaos, continuamente reimpresa. Véase también Herbert Schnädelbach, La filosofía de la historia después de Hegel, ed. Alfa, Buenos Aires 1980 (si bien Hegel tuvo una influencia arrolladora, no faltaron voces disidentes desde un principio; la más notable es quizá Jacob Burckhardt, Reflexiones sobre la historia universal, FCE, México 1943, pp 4-5). Sobre Hegel mismo, puede verse Jean Hyppolite, Introducción a la filosofía de la historia de Hegel, ed. Calden, Montevideo 1981.

Ya en el siglo XX, y no obstante las críticas que se han formulado, ha habido historiadores teóricos o filósofos de la historia, que han planteado problemas o concepciones de largo alcance o han intentado interpretaciones sugestivas, que han tenido gran predicamento, total o parcialmente, en diversas partes de Occidente. Las principales, a mi criterio, podrían ser las siguientes: Oswald Spengler, La decadencia de Occidente, edit. Espasa-Calpe, 2 tomos, varias ediciones (tuvo un influjo devastador, y si bien hoy está muy superada, no ha perdido el interés para los estudiosos); Arnold J. Toynbee, Estudio de la historia, edit. Emecé, 15 volúmenes, Buenos Aires, 1953-1960 (en inglés en 10 volúmenes, a los que luego se añadieron dos más, no traducidos; existe un resumen de la obra en dos volúmenes hecho por D.C. Somervell, que ayudó a popularizarla, y de la cual hay traducción a varios idiomas; al final de su vida, el mismo Toynbee sintetizó y revisó toda su obra: La historia, edit. Noguer, Barcelona 1975; Toynbee es seguramente entre los historiadores del siglo XX, el más popular y el más leído); Benedetto Croce, Teoría e historia de la historiografía, ed. Imán, Buenos Aires, 1953 y La historia como hazaña de la libertad, FCE, México, 1942 (la obra en italiano tiene otro nombre: la historia como pensamiento y como acción); José Ortega y Gasset, Historia como sistema (1941) en «Obras completas», tomo VI, edic. Revista de Occidente, varias ediciones (Ortega tiene muchos ensayos dedicados al tema, y además un inconcluso trabajo sobre Toynbee que ha sido publicado póstumamente); Karl Jaspers, Origen y meta de la historia, edit. Revista de Occidente, 
Madrid 1951, hay ediciones posteriores (el autor es uno de los grandes filósofos alemanes de este siglo, si bien acabó sus días en Suiza; de formación médica, se dedicó luego a la filosofía y es considerado uno de los autores más representativos de la corriente existencialista, de cuño cristiano; su marginal dedicación a los temas históricos ha tenido, sin embargo, un gran predicamento); Raymond R. Aron, Introducción a la filosofía de la historia, edit. Losada, Buenos Aires 1946 y Lecciones sobre la historia, FCE, México 1996 (editadas póstumamente). Aron, una de las mentalidades conservadoras más notables de Europa, fue muy criticado por las corrientes contestatarias, pero el vigor de su obra ha sobrevivido a tales críticos. Una visión panorámica, cf. J. Vogt, El concepto de la historia de Ranke a Toynbee, Guadarrama, Madrid 1967; sobre los problemas últimos, aún cuando con resabios marxistas, cf. Josep Fontana, La historia después del fin de la historia, Crítica, Barcelona 1992.

La historia constitucional en el mundo occidental es muy cotizada y cuenta, desde el siglo pasado, con textos básicos; aquí daremos una visión panorámica de esa bibliografía por países, que nos puede servir como referencia, para ver enfoques, períodos y métodos de trabajo.

1) Inglaterra; William Stubbs, Histoire constitutionnelle de I'Angleterre, V. Girard et Briere, 3 tomos, París 1907-1927; se trata de una obra cumbre del gran historiador británico muerto en 1901; el original en inglés no he podido consultarlo; F.W. Maitland, The constitutional history of England, Cambridge 1963.

2) Francia; M.Jallut, Histoire constitutionelle de la France, 2 vols. Ed. Du Scorpion, París 1956; J.J. Chevalier Histoire des institutions et des regimes politiques de la France de 1789 a nos jours ${ }_{2}$ LGLJ, Paris 1972; veáse también el interesante número 50 de la revista "Pouvoirs", dedicado a la histoire constitutionnelle, con motivo del bicentenario de la Revolución francesa: 1789-1989;

3) Estados Unidos de América; A.C. McLaughlin, A constitutional bistory of the United States, N.Y., 1953 (es considerada un clásico); Carl B. Swisher American constitutional development, H. Mifflin Co, Boston 1943 (hay traducción castellana); Edward S. Corwin, American constitutional history, Harper and Row, N.Y. 1964 (ensayos sueltos, de 
gran agudeza, escritos por quien es considerado el mejor constitucionalista norteamericano del siglo). Sin embargo, en los Estados Unidos, parte importante de su vida constitucional, está moldeada por la Corte Suprema y sus decisiones; en tal sentido, un análisis de esta célebre institución es obligado para el estudioso; cf. Bernard Schwartz, A bistory of the Supreme Court, Oxford University Press, N.Y. 1995;

4) España; Luis Sánchez Agesta, Historia del constitucionalismo español; CEC, Madrid 1984 (sigue siendo el texto clásico); Francisco Fernández Segado, Las constituciones históricas españolas, Ed. Civitas, Madrid 1986; Bartolomé Clavero, Manual de historia constitucional de España, Alianza, Madrid 1989.

5) Italia; Carlo Ghisalberti, Storia costituzionale d'Italia (18481948), 2 tomos, editori Laterza, Bari 1977.

6) Argentina; Germán J.Bidart Campos, Historia política y constitucional argentina, EDIAR, 3 tomos, Buenos Aires 1976-1977; Alfredo Galleti, Historia constitucional argentina, edit. Platense, 2 tomos, $\mathrm{La}$ Plata 1972 (parte de la época hispánica, y es uno de los poquísimos libros sobre la materia que está precedido por un análisis teórico de la disciplina; la obra quedó inconclusa); Dardo Pérez Guilhou, Ensayo sobre la historia político-institucional de Mendoza, Senado de la Nación, Buenos Aires 1977, e Historia de la originalidad constitucional argentina, Instituto Argentino de Estudios Constitucionales y Políticos, Mendoza 1994.

7) México; Emilio O. Rabasa, Historia de las constituciones mexicanas; UNAM, México 1994; Ernesto de la Torre Villar y Jorge Mario García Laguardia, Desarrollo histórico del constitucionalismo hispanoamericano, UNAM, México 1976(es una primera parte no continuada, que abarca tan sólo México, Centro-américa y el Caribe); Toribio Esquivel Obregón, Prolegómemos a la historia constitucional de México, UNAM, México 1980 (fragmento póstumo escrito por el gran historiador mexicano para continuar su clásica y monumental Historia del derecho en México, y del que sólo alcanzó a preparar un fragmento que, partiendo de la época hispánica, llega hasta los inicios del siglo XIX);

8) Venezuela; la obra maestra es la de José Gil Fortoul, Historia constitucional de Venezuela, Ministerio de Educación, 3 tomos, Caracas 1954, hay ediciones posteriores; una completa historia venezolana, 
en cuanto sintesis panorámica, puede verse en Allan R. Brewer-Carías, Instituciones políticas y constitucionales, Edit. Jurídica Venezolana y Univ. Católica del Tachira, Caracas 1996, tomo I.

9) Chile; Fernando Campos Harriet, Historia constitucional de Chile, Edit. Jurídica de Chile, Santiago 1983;

10) Colombia; Antonio José Rivadeneira V., Historia constitucional de Colombia, (1510-1978) edit. Horizontes, Bogotá 1978. Aparte deben verse los numerosos trabajos históricos de Carlos Restrepo Piedrahita, centrados, sobre todo, en el siglo XX (aspectos puntuales y una edición crítica de las constituciones de Colombia en el siglo pasado, cuando existía una estructura federal de gobierno).

11) Costa Rica; Mario Alberto Jiménez Quesada, Desarrollo constitucional de Costa Rica, edit. Juricentro, San José 1992;

12) Brasil; Paulo Bonavides y Paes de Andrade, História constitucional do Brasil, Brasilia 1990; y

13) Guatemala: Jorge Mario García Laguardia, Orígenes de la democracia constitucional en Centro América, EDUCA, San José 1971, hay ediciones posteriores (este autor tiene numerosos ensayos sobre la historia constitucional de Guatemala y sus países vecinos).

Hemos afirmado que por constitucionalismo debe entenderse el que se inicia a fines del siglo XVIII y a ambos lados del Atlántico, y en consecuencia, que de ahí debe partir nuestra periodificación histórica y también nuestros análisis. Pero esta división, no siempre es observada por los estudiosos, y esto por varias razones; a) porque sin lugar a dudas, y por lo menos en los pueblos europeos, la conquista del régimen constitucional se alcanza luego de largos esfuerzos que tienen un desarrollo histórico del que no hay que prescindir, si bien luego se condensan en un determinado período, b) porque en realidad, con el advenimiento del constitucionalismo aparecen muchas cosas nuevas, pero muchas que son muy antiguas permanecen tal cual o se adaptan, con lo cual hay que buscar sus orígenes, y c) finalmente, por cuanto la palabra constitución no es unívoca, sino multívoca, y ello permite, por lo menos en aras del uso del nombre y del contenido que a él se quiera dar, que se puedan rastrear antecedentes. En tal sentido y sobre todo en relación con los pueblos europeos, esto se hace con frecuencia, y en cierto sen- 
tido, es legítimo. Así, proceden algunos historiadores, como es el caso de un autor clásico, Charles H. Mcllwain, Constitucionalismo antiguo y moderno, edit. Nova, Buenos Aires 1958 (hay una reciente traducción española); este autor parte de Aristóteles, atraviesa la Edad media y cruza los tiempos modernos, hasta poco antes de los sucesos aluvionales del siglo XVIII. Por ejemplo, R.C. van Caenegem An historical introduction to the western constitutional law, Cambridge University Press, 1995, plantea como punto de partida la caída del Imperio romano de Occidente, o sea, en el siglo V, y desde ahí empieza a seguir los elementos que luego conformarían el concepto y modelo constitucional europeo. Por cierto, esto es plenamente válido en el caso de Inglaterra, como puede verse en la obra de Stubbs, que se remonta hasta la Carta Magna y aun antes; sin embargo, los hombres libres de los que habla el célebre documento inglés son los nobles, esto es, los barones, y no el hombre común y corriente y el texto, en puridad, es una reafirmación de viejas prerrogativas nobiliarias y no una concesión popular y democrática. Pero en otros pueblos, que no han tenido un pasado constitucional, como es el caso de Alemania, es dudoso que se pueda retrotraer la historia tan lejos. $O$ peor aún, en el caso de pueblos sometidos a tutela colonial, como es la América española. Así, Galletti; por ejemplo, parte del Virreynato del Río de la Plata, y aún antes, para explicar la historia constitucional argentina, lo que puede ser valioso como antecedente histórico de lo que sucedería después, pero no como parte constitucional, lo cual parece a primera vista muy forzado. En el caso del Perú, sería válido retrotraerse a la Carta de Cadiz, que aquí fue jurada y aplicada, pero no antes, o en todo caso, muy eventualmente a los movimientos precursores que se dan desde 1780, pero sólo en la medida que adelantan la idea emancipadora y no el simple movimiento de las instituciones. Creemos, pues, que, a) debe tenerse presente que el constitucionalismo en sentido estricto nace en realidad a partir del siglo XVIII con la colaboración, evidente, de Inglaterra, que crea, en su larga historia, el régimen constitucional, pero que curiosamente sólo lo consolida bien entrado el siglo XIX; b) que si bien lo anterior es cierto, nada impide que, en determinados pueblos, como es el caso de Francia y Estados Unidos, se vaya más allá para buscar esos mismos elementos formativos, que sin solución de continuidad, pasaron a formar, precisamente, el legado constitucional de esos pueblos, c) que desde el punto de vista de una historia global, comprensiva, es factible 
ir más allá, remontarse en la investigación en busca de antecedentes, y así hasta los más antiguos tiempos, pero con la salvedad de que estamos ante antecedentes, unos más forjados que otros, y en todo caso, de constitucionalismos imperfectos, que sólo adquieren valor desde la perspectiva que otorga el siglo XVIII, y no antes; aún más, su estudio como antecedente es útil, pero, insisto, en aquellos pueblos en los cuales tales antecedentes contribuyeron a crear algo que a la larga fué significativo para el constitucionalismo.

Por cierto, este enfoque, que entendemos estricto, no impide, recurrir siempre al pasado, que es una tendencia que se da en todos los tiempos. Hemos visto, incluso, como algunos tratadistas han intentado encontrar antecedentes del leasing en la Edad media o como otros han creído encontrar las raíces del Estado de bienestar entre aztecas e incas. Por tanto, hay que tomar estos antecedentes, con las precauciones del caso, ver como los manejamos y detectar en ellos nuestros propios intereses.

Otros, por el contrario, como Giovanni Sartori (cf. Elementos de teoría política, Alianza, Madrid 1992) señalan que a su criterio el único constitucionalismo que interesa es el moderno, o sea, el que nace a fines del siglo XVIII; los demás son antecedentes, muchos de ellos remotos, y otros totalmente inatingentes. Sartori señala como la palabra latina constitutio como edicto del Emperador, tenía en el Imperio un sentido totalmente distinto del actual; y que además, la traducción del griego politeia (que usan Platón y Aristóteles) por nuestra moderna palabra constitución, es otra de las arbitrariedades de los traductores (traduttore, traditore). En igual sentido, añade, cuando se traduce polis por estado o ciudad-estado, lo único que se hace es embrollar más el concepto, antes que aclararlo (las palabras griegas polis, politeia, politiká, zoon politikón, se prestan a múltiples traducciones, por la dificultad del trasvase de una lengua a otra, según señala Carlos García Gual, en el prólogo a Política de Aristóteles, edit. Alianza, Madrid 1995, traducida por él y Aurelio Pérez Jiménez).

Si bien existe un consenso de que la historia se ocupa del pasado, la dificultad empieza cuando se quiere definir ese pasado y a partir de cuando debe tenerse en cuenta. Por cierto, cuando nos referimos al pasado, hacemos sin querer, una referencia al tiempo; tiempo pasado, 
tiempo presente y tiempo futuro. Aquí vienen a cuento las insuperables reflexiones de San Agustín sobre el tiempo (Confesiones, libro $\mathrm{XI}$ ), que son clásicas. El obispo de Hipona dice que es casi imposible definir el tiempo: si no me preguntas que es, lo sé; pero si me pides que diga lo que es, no lo sé. Según el santo, no existiría el pasado, sino solo el presente del tiempo pasado. Por tanto, decir qué es pasado, es complicado. Como -siempre según San Agustín- vivimos el presente- a la larga todo lo que dejó de ser es pasado, y por lo tanto, pasado sería, en rigor, lo que sucedió hace un minuto; por tanto, el pasado sería, en sentido amplio, lo que sucedió ayer.

Pero el problema no se detiene aquí. Es curioso señalar como Herodoto, considerado como el padre de la Historia, contaba cosas que veía o de las que había tenido noticia cierta; tanto él como Tucídides hablan prácticamente de lo presente, o si se quiere, de lo existente y muy cercano (Historias, II, 9, Historia de la guerra del Peloponeso, I, 73). Por otro lado, la voz historia viene del griego istor, que significa ver. Por tanto, al parecer la historia sería historia del presente. Pero en el siglo XIX, la historiografía clásica consagró el pasado como objeto de la historia y el documento como la fuente del historiador. Lo cual en sustancia es correcto, pero nos queda por resolver cuando ese pasado es pasado. Algunos, así, distinguieron entre historia (pasado estudiado rigurosamente) de la crónica (que trata de lo contemporáneo). En igual sentido, muchos historiadores que trataban el presente, lo hacían con alguna distancia; se detenían a 20 ó 30 años de donde estaban, para que la cercanía no alterase la visión de conjunto. Entre nosotros, la monumental Historia de Basadre, completada prácticamente en la década de 1970, se detiene en 1933; el célebre historiador no fue o no quiso acercarse más a los hechos.

Sin embargo, aún aceptando que el pasado es el núcleo central de la historia, no todos lo aceptan estrictamente, o en todo caso, tienen un concepto muy flexible de lo que es el pasado. Por ejemplo, Armando Saitta, en su Guía crítica de la historia y de la historiografía, cit, dice que lo que ha detenido o mediatizado hacer una historia contemporánea son tres tipos de argumentos: i) la dificultad de acceder a las fuentes; ii) la falta de distanciamiento necesario entre el historiador y su objeto de análisis, y iii) la ausencia de una perspectiva, ya que el proceso histórico no ha concluido aún y está en movimiento (p. 19). Según Saitta, estos argumentos son inaceptables, y en todo caso fáciles de 
sortear, pues el fin esencial de la historia es comprobar los hechos y reconstruirlos, pero sobre todo, explicarlos. Aún más, en el actual estado de la cuestión, vemos que, con frecuencia, los historiadores incursionan en los tiempos presentes, y con bastante éxito (lo cual no quiere decir que sus enfoques no puedan variarse el día de mañana). Así, tenemos, la reciente Historia del siglo $\mathrm{XX}$ que Eric Hobsbawn acaba de editar, y que cubre lo que él llama el corto siglo $X X$, que abarca de 1914 a 1991. El libro, en su edición original en inglés fue publicado en 1994, y traducido casi de inmediato al castellano.

Si todo esto lo aplicamos al siglo XX peruano, y en lo que a historia constitucional se refiere, pensamos que nada nos impide avanzar hasta el presente, si bien este presente puede coincidir con algún hecho o suceso importante; como pudiera ser el año 1993, que representa la sanción de una nueva Constitución, luego del golpe de Estado de 1992 y que marca el inicio del período autocrático.

Un concepto importante, que aquí no hemos tratado, es el de constitución histórica distinto a todos los membretes que hemos usado como equivalentes a historia constitucional (cf. sobre este punto, cf. Dardo Pérez Guilhou, "Poder constituyente y constitución histórica argentina", en AA.VV. El régimen constitucional argentino, Idearium, Mendoza 1984 y Domingo García Belaunde, La constitución histórica y la reelección presidencial en Scribas, núm. 3, 1997). En efecto, por un lado tenemos la historia constitucional y todos sus equivalentes, y que es el nombre de una disciplina histórica que estudia el pasado en relación con el desarrollo constitucional de un pueblo. Por otro, está la constitución histórica, que es un concepto en cierto sentido categorial, y que da a entender la existencia de líneas de tendencia que configuran una manera de ser de una determinada comunidad política y que se ha formado en el transcurso del tiempo. Lo que no siempre queda claro es cuál es la relación entre la constitución histórica y la constitución positiva o dogmática; que puede ser de sintonía o de desfase, total o parcial. En Inglaterra, el problema no existe, pues su constitución histórica es su constitución actual y vigente, por lo menos, en sentido sustantivo (así lo señala claramente Jennings); en otros países esto no siempre sucede; a veces la constitución histórica orienta a un pueblo, pero a veces no lo hace. En el caso del Perú, hay ciertos temas que son 
parte de su constitución histórica, como por ejemplo, su existencia republicana, la división de poderes, por lo menos en su clásica versión tripartita; la no reelección presidencial, aún cuando ahora esté amenazada y no sabemos si quedará o no; el respeto de las libertades fundamentales, en el sentido de las clásicas, etc. Por un lado tendríamos la historia constitucional, o historia de las constituciones, etc., que sería el continente, y por otro, la constitución histórica, como torrente jurídico temporal, que sería el contenido. Creemos que con esto es suficiente para detectar la existencia de ambas y sus claras diferencias: la primera, una disciplina formal, histórica, la segunda una realidad permanente en el tiempo, que debe ser estudiada, y que, conjuntamente con otros hechos circunstanciales y de coyuntura, forman nuestra historia constitucional.

En cuanto a cómo hacer historia constitucional, puede ser de varias maneras; así, cabe una historia lineal, que puede ser larga o corta. Por ejemplo, podemos escribir una historia constitucional del siglo XIX; aquí estamos ante un complejo de hechos que ocupan casi un siglo. Pero podemos hacer una historia lineal corta, como por ejemplo, si estudiamos sólo la Constitución de 1839, conocida como Constitución de Huancayo. En este último caso, lo que tendríamos pendiente sería, a) estudiar los antecedentes de porqué ella se dio, como es el caso de la derrota de los confederados; b) ver cómo fueron los debates y que se discutió, c) ver los alcances del articulado, como fue la legislación de desarrollo y eventualmente, su aplicación por los tribunales, d) ver los debates doctrinarios que se suscitaron, e) detectar su vigencia política y sus problemas de aplicación, f) finalmente, su crisis y derogación.

Por otro lado, cabe hacer historias verticales, como podría ser un análisis sectorial en el tiempo de algunas instituciones; en este sentido, es clásico el estudio de Villarán sobre los ministros en el Perú; recientemente ha hecho lo mismo Pedro Planas, en relación a la descentralización en el Perú republicano.

Sin embargo, hay que descartar lo que podría desprenderse de Emilio Ravignani en la década del 30 (sigo a Galletti en su Historia ya citada). Según creía ver Ravignani, habría que distinguir entre historia constitucional e historia de las constituciones. Esta última sería, casi un análisis literal y exégetico, mientras que aquélla sería un estudio global y 
comprensivo. La diferencia que podría desprenderse de Ravignani, me parece artificiosa y en cierto sentido contraproducente. En realidad, no calza con el estado de la investigación histórica. Veamos como: a) los estudiosos de la historia constitucional, por lo menos, en Occidente, han utilizado diversos nombres para sus investigaciones, pero prefiriendo, como hemos seńalado, el de historia constitucional, b) por esta razón de mayor uso, es que he optado por ella, siendo conciente que el nombre no es definitivo, pero reconociendo su utilidad, pues es el que utiliza la comunidad científica; c) lo que apuntaría Ravignani es un problema más serio, cual es el enfoque teórico de la disciplina; esto es, apartarse del análisis exegético y legalista, e ir al fondo del asunto, en lo cual tiene razón. O sea, lo que interesa no es el nombre, sino la metodología de estudio, que dicho sea de paso, no es propio ni privativo de la historia constitucional, sino de los historiadores del derecho. Dicho en otras palabras, son los historiadores lo que sientan las bases teóricas y la metodología, y de ahí lo toman los historiadores del derecho y, por cierto, los historiadores constitucionales. Aquel enfoque que consiste en el estudio del articulado, y centrado en la legislación, se usó en una época, pero ya no se estila más. Por tanto, me parece innecesario armar toda una discusión teórica sobre la base de un método totalmente superado.

En el Perú, la historia del derecho se enseñó desde muy temprano. Román Alzamora fundó la primera cátedra en la Universidad de San Marcos en 1875, que curiosamente fue la primera en funcionar en América Latina; Alzamora, hijo de su época, en su curso publicado al año siguiente (Curso de Historia del Derecho Peruano, Imp. del Estado, Lima 1876), se limitó a hacer rescates exegéticos y legalistas que hoy, por cierto, nadie hace. Si bien existen algunos ensayos aislados, quien pone las bases de la historia del derecho en el Perú, en sus dos fases, es Jorge Basadre, en dos grandes obras, Historia del derecho peruano, Lima 1937, presentada como primer tomo, pero nunca continuada, y que cierra todo un período; y luego Los fundamentos de la historia del derecho, Lima 1956, que presenta las corrientes más de moda, demostrando así que vivió en permanente revisión de sus postulados. Si bien ya no escribió nada orgánico sobre los aspectos teóricos de la disciplina, volvió sobre ellos en las sucesivas ediciones de su Historia de la República del Perú y en su Introducción a las bases documentales [...] de 1971 (en los prólogos a dichas obras) y en ensa- 
yos sueltos; así, por ejemplo, en su libro El azar en la historia y sus límites, Lima 1973. Después de Basadre, han incursionado en la historia del derecho, entre otros, Javier Vargas, Vicente Ugarte del Pino, Franklin Pease G.Y., Luis H. Pásara, Fernando de Trazegnies Granda (quien ha tenido el mérito de haber impulsado sus estudios y ha formado mucha gente, que está dando sus frutos, como es el caso de Carlos Ramos Núñez, Jorge A. Guevara Gil y René Ortiz), Jorge Basadre Ayulo y Francisco José del Solar.

Sobre historia constitucional existe muy poco, como puede verse de la bibliografía señalada en el texto (desde Toribio Pacheco en el siglo pasado, hasta las contribuciones de José Pareja Paz-Soldán). Recientemente tenemos; Pedro Planas, La república autocrática, Fundación Ebert, Lima 1994; ib, La descentralización en el Perú republicano (1821-1998), Municipalidad Metropolitana de Lima, Lima 1998; José F. Palomino Manchego, estudio preliminar a Toribio Pacheco, Cuestiones constitucionales con prólogo de Domingo García Belaunde, editorial Grijley, Lima 1996; Edgar Carpio Marcos, "La primera cátedra peruana de derecho constitucional», en ICPDC (Huancayo) núm. 5, 1996; ib, "La enseñanza del derecho constitucional en la Facultad de Ciencias Políticas y Administrativas de San Marcos (1873-1922)" en Apuntes de Derecho, año III, núm. 1, mayo de 1998; Carlos F. Mesía Ramírez, El pensamiento constitucional en el Perú del siglo XIX, Tesis de Magister en Derecho Constitucional, PUC, Lima 1997; Daniel Soria Luján, Los mecanismos iniciales de defensa de la Constitución en el Perú; el poder conservador y el Consejo de Estado (1839-1855); Tesis para optar el título profesional de Abogado en la Facultad de Derecho de la Universidad Católica, Lima 1997; Oscar Díaz Muñoz, La moción de censura en el Perú, con prólogo de Francisco Fernández Segado, Ara editores, Lima 1997; Valentín Paniagua C., "Las relaciones legislativo-ejecutivo», en Ius et Praxis, núm. 19-20; diciembre de 1992; ib. Constitucionalismo, autocracia y autoritarismo, en Scribas, núm. 4 1998. Sobre periodificación de nuestra historia constitucional, cf. Domingo García Belaunde, Los inicios del constitucionalismo peruano, en «Pensamiento Constitucional», núm. 4, 1997; y La constitución en el péndulo, UNSA, Arequipa 1996; esp. pp. 1-33. 